João Paulo Garrido Pimenta

Professor no Departamento de

História da Universidade de São

Paulo (FFLCH/USP - São Paulo/

Brasil)

e-mail: jgarrido@usp.br
FRASQUET, Ivana.

Las caras del águila: del liberalismo gaditano a la república federal mexicana, 1820-1824.

Castelló de la Plana: Publicacions de la Universitat Jaume I, 2008. 382p. (Colección América, 11)

\section{A formação do México, entre a Espanha e a América}

Fruto de tese de doutoramento defendida em 2004 na Universitat Jaume I de Castellón e dirigida por Manuel Chust, o livro de Ivana Frasquet é contribuição historiográfica de peso. Não apenas porque vivemos tempos de hiperprodutividade acadêmica a resultar, no campo historiográfico, em uma enormidade de superficialidades e efemeridades - situação acentuada pela recente onda de comemorações dos supostos bicentenários das independências da América espanhola, a mesclar pontuais verdadeiras contribuições acadêmicas com uma montanha de redundâncias ou de ideias apenas rabiscadas; mas, sobretudo, porque a obra de Frasquet é boa por ela mesma, feliz encontro de um tema extremamente relevante com uma pesquisadora de alto nível que o conhece tão bem quanto dele gosta.

A independência do Vice Reino de Nova Espanha e a subsequente formação do Estado nacional mexicano são pautas que há muitas décadas têm merecido atenção de grande número de cientistas sociais, sobretudo os historiadores. Muitos mexicanos, vários norte-americanos e canadenses, poucos europeus; dentre estes, os espanhóis delimitam um círculo mais restrito ainda. Um mérito de antemão ao estudo de Frasquet? Em parte sim; mas apenas em parte, já que a pretensão da autora - tanto em Las caras del águila como no restante de sua numerosa produção tematicamente a ela correlata - não é, simplesmente, tratar de um tema de que seus conterrâneos pouco trataram. Essa eventual postura, ao mesmo tempo presunçosa e ingênua, é a de muitos historiadores de muitas histórias de muitos paises, mas não a de Frasquet. É como uma historiadora do chamado liberalismo hispânico e da história mexicana em seus desenvolvimentos oitocentistas que ela deve ser efetivamente tomada, e é por aí que sua obra segue.

Os grandes temas de uma historiografia nacional não se esgotam jamais, todos sabemos. 0 caso aqui presente não é diferente. Conforme bem mostraram avaliações ao mesmo tempo quantitativas e qualitativas da numerosíssima historiografia acerca da formação do Estado mexicano, reunidas por Alfredo Ávila e Virginia Guedea ainda antes dos bicentenários (La independencia de México: temas e interpretaciones recentes. México: UNAM, 2007), o muito que se fez mostra o muito que não se fez, e, claro, a permanente reinvenção de tal objeto historiográfico. Frasquet encontra em seu livro um filão original, apenas parcialmente explorado por uma historiografia pretérita e da qual em vários momentos ela se mostra tributária (a de autores como Nettie Lee Benson, Jaime E. Rodríguez e do próprio Manuel Chust): os impactos das experiências político-constitucionais espanholas peninsulares (logo hispânicas) na definição de um movimento histórico que, na América, levaria à formação do Estado nacional mexicano. A delimitação cronológica de sua obra implica uma circunscrição: a ela importa sobremaneira o que se passa entre a eclosão da segunda onda constitucional espanhola, em 1820 (com a pronta reunião de novas cortes

DOI - http://dx.doi.org/10.1590/2236-463320120312

Almanack. Guarulhos, n.03, p.152-156, 1º semestre de 2012

resenhas 
nacionais nas quais a deputação da Nova Espanha desempenharia papel paradigmático), e a queda da efêmera experiência monárquica mexicana, com a proclamação da Ata Federal de 1823. Cádiz e as Cortes de 18101814 se fazem fortemente presentes na análise, mas como manancial do que se passa nos momentos mais cruciais de definição da independência e da formação do Estado que realmente interessam à autora.

0 tema e sua delimitação temporal, por si sós, impõem um corte documental à autora, que realiza, então, uma minuciosa e aprofundada leitura de debates parlamentares, madrilenhos e novohispanos/mexicanos (há outra documentação variada complementar). De tal leitura resulta uma análise do problema central que é, simultaneamente, uma narrativa, passo a passo, do que pensaram, disseram e fizeram homens atuantes naqueles espaços parlamentares, cruzada com o essencial do que, em termos políticos, se passava fora deles, na Espanha, na Nova Espanha e no México. Uma "história política" (que prefiro chamar, apenas, de "uma história focada no político", sem qualquer pretensão categorial) que muitos consideram fora de moda em afãs novidadescos pouco dignos de nota, mas que obras como as de Frasquet contribuem para tornar incontornável.

Ao longo de oito capítulos cronologicamente sequenciados que agrupam as quase quatrocentas páginas da obra, recheadas de citações primárias, menos de citações secundárias (que, afinal, são secundárias), Frasquet nos oferece magnificamente os ritmos e as direções de uma política construída em espaços parlamentares, permeada de embates, contradições, meias-palavras e mudanças repentinas de posição, em meio à qual discerne, de modo enfático, os momentos em que o constitucionalismo espanhol de Cádiz e de Madri se metaboliza em um constitucionalismo agora americano, também mexicano, ao fim e ao cabo hispânico; por vezes, momentos até mesmo em que aquele constitucionalismo é continuidade, isto é, oferece parâmetro de ação, porto seguro para a prática política dos legisladores americanos.

Ponto fundamental de sua tese é a constatação de que a atuação dos deputados de Nova Espanha nas Cortes de Madri tenha se pautado, até junho de 1821, por sinceras tentativas de construção de uma entidade política que abrigasse tanto a Espanha quanto o que restava de seus antigos domínios americanos, em um arranjo político que contemplasse as demandas de autonomia - não de independência - que aqueles deputados expunham. Afinal, será do esgotamento desta alternativa, resultado de um errático processo de embates nas Cortes nos quais diferenças políticas até então concebidas majoritariamente como pequenas se transformaram em verdadeiras incompatibilidades entre peninsulares e americanos, que emergirá um senso de distinção entre espanhóis americanos novohispanos e peninsulares capaz de, ai sim, amparar um projeto de total separação entre as partes (o paralelismo com o caso lusoamericano salta aos olhos. Quem se arriscará a enfrentá-lo?). Uma vez voltados para a construção de um novo Estado, tais deputados, ao irradiarem uma experiência e um conjunto de saberes, inspirações e modelos a outros indivíduos que com eles passariam a atuar no legislativo mexicano, seriam o elo mais concreto a interligar Espanha e México, tecendo os fios de um constitucionalismo que Ihes serviu de parâmetro de ação em meio aos turbulentos anos de 1822 e 1823.

De um autonomismo hispano-americano a um autonomismo provincial mexicano (base da república federal de 1824), passando por uma revolução de independência que redefiniu não apenas os agentes de uma questão nacional, 
mas sua própria natureza (embora Frasquet seja pouco cuidadosa no tratamento deste arcabouço teórico importante, sobretudo ao utilizar de modo impreciso o termo nacionalismo nos três primeiros capítulos do livro), eis a síntese de uma trajetória complexa, que aqui ganha especial concretude.

Para tanto, contribui a arquitetura geral da obra, assentada em uma permanente reiteração, ao longo do livro, da tese central de sua autora. Leiamos então, suas próprias palavras. Logo em sua "Introducción", afirma, a propósito de uma das "pontas" de seu recorte cronológico: "La participación de los diputados americanos, novohispanos concretamente, en las Cortes de Madrid de 1820 será de gran importancia para la consecución de las aspiraciones autonomistas de este grupo" (p.19); e, quanto à outra "ponta", que "a partir de aquí [1822], el liberalismo mexicano aglutinará a todas las facciones que, de uma manera u outra, estaban luchando por la independencia de México. Insurgentes, autonomistas, liberales, monárquicos, republicanos, federalistas, centralistas, etc., todos se unirán para conformar el Estado-nación mexicano, eso sí, partiendo del liberalismo hispano que la legislación doceañista y la Carta de 1812 habian dejado en herencia a los diputados novohispanos" (p.21.) Logo em seguida, um cauteloso e benéfico esclarecimento:

\footnotetext{
Con eso no queremos decir que toda la obra de los constituyentes mexicanos sea fruto de la legislación doceañista, ni mucho menos. Pero sí queremos resaltar el espacio que el liberalismo hispano, que no español, nacido de las Cortes de Cádiz tuvo en la formación del Estado-nación mexicano. Desde nuestra visión global, integradora e contextualizada, no se puede explicar Cádiz sin América, ni América sin Cádiz (p.21)
}

Tese exposta e devidamente circunscrita, Frasquet dá início ao seu empreendimento, repitamos, com o fôlego que ele exige; embora exigisse também um tratamento mais circunspecto e polissêmico de termos como liberalismo, federalismo e monarquismo, a respeitar uma dinâmica conceitual com a qual a autora não se preocupou (vide os trabalhos de outro historiador espanhol, Javier Fernández Sebastián, não aproveitados por Frasquet). Como quer que seja, vemos sua tese central reiterada em muitas passagens do texto, relativas a fenômenos específicos por meio dos quais revelar-se-iam formas pelas quais a América continuava a se fazer parte do mundo hispânico. Assim, por exemplo, em 1822 "la frustración autonómica había desembocado en un deseo de independencia sentado sobre las bases del constitucionalismo hispano desarrollado en Cádiz" (p.100); ou "la independencia había sido posible gracias al trabajo de los autonomistas mexicanos que tenían en las Cortes de Cádiz y en la Constitución de 1812 el legado político y parlamentário que formaba parte de su tradición hispana" (p.121); finalmente, "la Constitución de 1812 y sus leyes eran el referente legislativo y liberal de los diputados mexicanos en la construcción de su próprio Estado-nación" (p.199), afirmação reiterada tal qual para o que ocorria em março de 1823 (p.291-292), quando "continuaba así el liberalismo mexicano el caminho iniciado en Cádiz sobre la concepción de los poderes" (p.300). Em suma,

Cádiz seguia siendo útil para sentar las bases de la construcción del Estado-nación mexicano, jen 1823 ! Y en un Estado que, como se insinuaba en el último artículo [das proposições apresentadas ao congresso mexicano em 07 de abril], caminaba hacia formas monárquicas de gobierno. ¿Sería eso posible? (p.307). 
A aparente perplexidade da autora perante o que ela observa e as interjeições de seu discurso possuem função retórica, para enfatizar a validade de sua tese central, da qual, aliás, o leitor dificilmente discordará. Ponto positivo, talvez o mais importante. No entanto, após repetidas reiterações que nos acompanham até as última página do último capítulo - o livro de Frasquet não possui "Conclusões" formalmente compostas - algo parece ter mudado nessa tese. Progressivamente, o que fora enunciado na "Introducción", primeiro ganha pertinência - com as consistentes demonstrações empíricas da autora -, para logo se converter em abandono de cautela e em ênfase excessiva. Ora, repitamos: há aqui um corte documental, que implica obviamente na segmentação de uma história (e não há outro modo de torná-la História). A formação do Estado mexicano se explica parcialmente pela continuidade modificada de conteúdos advindos das experiências constitucionais hispânicas. Com isso, certamente Frasquet se mostrará de acordo; de nossa parte, tal afirmação deve soar como uma valorização do que ela própria afirmou à p.21 (supra), e que parece ter ficado para trás à medida que seu livro caminha para o final. Algumas coisas se explicam por aí, muitas e fundamentais, mas claro que nem tudo.

É possível que esta crítica esteja antes confinada à análise formal do discurso de Frasquet do que ao grosso de sua análise histórica. De todo modo, suas conclusões corroboram a percepção desse progressivo abandono de cautela na reiteração de sua tese. Nas últimas páginas do capítulo 8, ainda é possível ler-se, sem freios, que "a la altura de 1823 con la forma republicana declarada, las províncias levantadas en pro de su soberania, con los españoles todavia en suelo mexicano, con la discusión sobre federalismo o centralismo... ¡la Constitución doceañista y toda la legislación hispana emanada de las Cortes de Cádiz y de las de Madrid eran todavia punto de referencia para la construcción del Estado-nación mexicano!" (como discordar da autora? Ao mesmo tempo, como não sentir falta de um matiz do tipo um dos pontos de referência importantes...?). E no último parágrafo do livro, deparamo-nos com uma dura crítica a "algunos autores" que teriam realizado análises da "herencia liberal hispana" na formação do México "desde el presentismo, desde el conocimiento de como sucedieron los hechos en décadas posteriores y desde otras ciencias no históricas", e que supostamente resultariam na impossibilidade de "que valoremos en su justa dimensión el impressionante cambio revolucionário que el liberalismo produjo en las sociedades del Antiguo Régimen" (p.367).

É razoável restringir o bom da historiografia ao que historiadores, digamos, de formação formal, fizeram? Ou imputar a todos os autores diretamente mencionados - José Antonio Aguilar, Roberto Breña, Rafael Rojas e Alfredo Ávila, referidos em rodapé, mas apenas parcialmente também na bibliografia final, e de posturas historiográficas bastante diferentes entre si - a pecha de anacrônicos? Minhas respostas são ambas negativas. Inclusive por que vejo em tais autores méritos e posturas em muitos casos perfeitamente compatíveis com muito daquilo que há no livro de Frasquet. Por exemplo, no fato de também eles (todos) terem se preocupado com as experiências constitucionais de Cádiz e de Madrid "lá" e "cá", jamais confinando os escopos de suas também excelentes análises aos limites geográficos ou intelectuais desenhados pelo nacionalismo historiográfico mexicano (o que, aliás, esvazia a mal-humorada crítica historiográfica realizada por Jaime Rodríguez em seu "Prefacio" a Las caras del águila). Mérito de todos os aqui citados; méritos, aliás, de 
muitos outros, por toda a parte, voltados às independências e às formações estatais nacionais a elas subsequentes.

Esse antagonismo entre o que se apresenta em Las caras del águila e o que se apresentou antes dele não implode, sequer esvazia muitos de seus méritos, alguns dos quais sequer mencionei - ou teria condições de mencionar - aqui. Se várias de suas passagens, marcadas por um desmedido embate historiográfico, dão a impressão de uma tese em tom excessivo e fecham portas ao debate, todo o resto abre muitas e muitas outras, função última de obras historiográficas reveladoras, pujantes e importantes, qualidades últimas - repitamos - a definirem o livro de Frasquet. 